\title{
Active moon: evidences from Chandrayaan-1 and the proposed Indian missions
}

\author{
Narendra Bhandari and Neeraj Srivastava
}

\begin{abstract}
Chandrayaan-1, the polar Lunar orbiter mission of Indian Space Research Organization, successfully carried out study of Moon's environment and surface processes for a period of about nine months during 2008-2009. The results obtained by the mission established (i) A tenuous but active hydrosphere (ii) Volcanically active and geologically dynamic Moon and (iii) Global melting of Moon's surface regions and formation of magma ocean early in the history of Moon. Chandrayaan-1 was equipped with a dozen instruments, including an impact probe, which housed three additional instruments. The results obtained by four instruments viz. Chandra's Altitudinal Composition Explorer, Moon Mineral Mapper $\left(\mathrm{M}^{3}\right)$, Solar Wind Monitor and Synthetic Aperture Radar gave an insight into an active hydrosphere, with several complex processes operating between lunar surface and its environment. These inferences are based on identification of $\mathrm{H}, \mathrm{OH}, \mathrm{H}_{2} \mathrm{O}, \mathrm{CO}_{2}$, Ar etc. in the lunar atmosphere. There are indications that several young ( 2 to100 Ma) volcanic regions are present on the Moon as shown by integrated studies using Terrain Mapping Camera and $\mathrm{M}^{3}$ of Chandrayaan-1 and data from other contemporary missions i.e. Kaguya and Lunar Reconnaissance Orbiter. These data establish that Moon has a dynamic and probably still active interior, in contrast to the generally accepted concept of dormant and quiet Moon. Discovery of Mg spinel anorthosites and finding of kilometer sized crystalline anorthosite exposures by $\mathrm{M}^{3}$ support the formation of global magma ocean on Moon and differentiation early in its evolutionary history. Furthermore, $\mathrm{X}$-ray Spectrometer data showed anorthositic terrain with composition, high in Al, poor in $\mathrm{Ca}$ and low in $\mathrm{Mg}$, Fe and $\mathrm{Ti}$ in a nearside southern highland region. This mission provided excellent opportunity for multilateral international cooperation and collaboration in instrumentation and observation in which a dozen countries participated and contributed to the success of the mission. The Mars Orbiter Mission, for study of Martian atmosphere and ionosphere was launched on 5th November, 2013 and is already on its way to Mars. This will be followed by Chandrayaan-2, a well equipped Orbiter-Lander-Rover mission. This article summarises a few results obtained by Chandrayaan-1, which changed some of the concepts about Moon's evolutionary history.
\end{abstract}

Keywords: Moon; Chandrayaan-1; Lunar hydrosphere; Lunar environment; Magma ocean; Recent volcanism

\section{Introduction}

The Indian Space Research Organisation (ISRO), with a humble beginning about 60 years ago, developed rockets, satellite building, communication, and remote sensing technologies. It acquired the capability of undertaking planetary exploration missions when the Polar Satellite Launch Vehicle (PSLV) was commissioned in 1995 and embarked on an ambitious program for study of planets in the solar system at the turn of the century. The first planetary mission was Chandrayaan-1, an orbiter mission to the Moon, which was realised in late 2008. We first give a brief historical background of the Indian Space Program,

* Correspondence: nnbhandari@yahoo.com

PLANEX, Physical Research Laboratory, Ahmedabad 380009, India describe the main scientific results of the Chandrayaan-1 mission and introduce the proposed missions, currently in progress.

\section{Earth-Moon system}

Processes on the Moon and the Earth are intimately related because they are bound by several common phenomena and their evolution mutually influence each other. Both of them are connected through gravitational forces and tidal interactions. Whereas the tidal forces have slowed down the earth's spin significantly over the aeons, measurements of Earth-Moon distance by Apollo missions has revealed that Moon is drifting away from Earth by 3 to $4 \mathrm{cms}$ every year. Extrapolating back in 
time, it has been determined that the Moon was very close to the Earth in the remote past. Furthermore, because of their proximity, both are subjected to the same population of micrometeorites and larger interplanetary objects, i.e. asteroids and comets and the same flux of solar and galactic cosmic ray particles. Based on its orbital peculiarities and chemical and isotopic analyses of Moon samples, the "Giant impact hypothesis" was proposed as discussed in various papers $[1,2]$ which indicates that Moon was formed from the material ejected from the Earth by impact of a large $\left(0.1 \mathrm{M}_{\mathrm{E}}\right)$ asteroid. From the study of impact melt breccias brought back by Apollo missions, it has been established that Moon and, by inference, Earth went through a period of intense bombardment of large interplanetary objects, 3.9 to 3.8 billion years ago. The energy deposited by some large impacts on the Earth was so high that the oceans would have evaporated, sterilizing it and making any life present extinct [3]. On the other hand, impacts could possibly bring in seeds of life and chemicals required for life to sustain on Earth. Consequences of large impacts on Moon are equally serious since they could have changed Moon's orientation. Wieczorek and Feuvre [4] have proposed that Moon's present antapex was apex in the past when the basins were formed and this change in the orientation of the Moon may have been brought about by the impact responsible for formation of the Smythii basin.

The Moon, itself, has affected the Earth and evolution of life on the Earth in important ways. Firstly, a large body like the Moon going around the Earth would stabilize the orbit of the Earth e.g. its wobble, to provide equitable climate so that extreme temperatures do not occur on the Earth. Secondly, Moon's tidal effects reduced the spin of the Earth from about 5 hour period to 24 hour period and thirdly the lunar tides brought marine life from seas, where life presumably originated, to land which slowly evolved into land-species. Many of these phenomena can best be studied from the Moon, because their records on the Earth have been obliterated by severe geological activities whereas they are reasonably well preserved on the Moon, which, to a great extent, is geologically quiet and dormant.

The Moon has been orbiting through the Earth's magneto tail, immersed in it for about 4 days every month. During these periods, its surface is exposed to electrons and the low energy ions trapped there, specifically to $\mathrm{H}$, $\mathrm{OH}, \mathrm{O}$ and $\mathrm{N}$, some of which may be of terrestrial origin (see e.g. [5]). Since the Moon has been very close to the Earth in the past, it has been exposed to terrestrial environment to some extent. All these considerations make the Moon an interesting object for scientific study [6] and therefore a scientific mission to the Moon with limited but well defined objectives was undertaken by ISRO.

\section{Historical perspective}

The Indian Space Program started in early 1960's when USA and USSR were already preparing for direct exploration of the Moon and sample return missions. The primary goal of ISRO's space program was to use space technology for national planning and social development. India being a vast agricultural country with diverse geologic formations, ranging from Himalayas in the north, desert in the west and Indian Ocean in the south, flanked by a long shore line and inaccessible hilly regions in the north east, the remote sensing observations, with its Indian Remote Sensing Satellite (IRS) series, soon found applications in resource identification, land and crop management, monsoon prediction, disaster management and urban planning etc. The other series of satellites, called INSAT, were used for communication, television, tele-education, tele-medicine, etc.

The capability of sending spacecrafts for exploration of planets was achieved in 1995 with the successful demonstration of the Polar Satellite Launch Vehicle but, in view of national priorities for remote sensing and communication, a debate on planetary exploration program was taken up later, in 1998. The first mission related to the solar system studies was a solar X-ray monitor from an Earth orbit, called SOXS, which was launched in 2002 [7]. In 2003, it was decided to carry out an orbiter mission to the Moon with focussed scientific objectives [8]. This mission was realised in 2008 with the launch of Chandrayaan-1. The primary objectives of this mission were topographic, mineral and chemical mapping of the lunar surface to understand the evolutionary history of the Moon and search for water and processes responsible for transport of volatiles on the lunar surface. To meet the objectives of the mission, remote sensing sensors, operating in the various electromagnetic wavelengths (from low energy gamma rays to radio), both in active and passive mode, as appropriate, were selected [8]. These included optical sensors viz. a panchromatic stereo camera for terrain mapping (TMC) and Hyper spectral sensors (HySI, SIR-2 and $\mathrm{M}^{3}$ ) for mineral mapping. The $\mathrm{M}^{3}$, with capability of spectral measurements from 0.4 to 3 microns, could detect absorption bands due to various constituents present at the lunar surface. A low energy (1 to $10 \mathrm{KeV}$ ) X-ray Spectrometer (C1XS) for chemical mapping using characteristic fluorescent X-rays and a High Energy X-ray Spectrometer (HEX), operating in low energy gamma ray region (30 to $300 \mathrm{KeV}$ ), for radioactivity mapping of uranium and thorium decay chain nuclides were used. Mini-SAR (mini Synthetic Aperture Radar) operated in the microwave region $(2.2 \mathrm{GHz})$, worked as scatterometer, altimeter and radiometer for study of surface and near-subsurface features and detection of signatures of water-ice. Neutrals and ions were studied by SARA (Sub-KeV Atom Reflecting Analyzer), designed to image the lunar surface using low energy neutral 
atoms (up to $\mathrm{Fe}$ ) in the energy range of $10 \mathrm{eV}$ to $2 \mathrm{KeV}$. It included a low energy Neutral Atom Censor (CENA) and a Solar Wind Monitor (SWIM) for solar wind studies. Radiation dose measurements were carried out by RADOM (Radiation Monitor). CHACE, consisting of a quadrupole mass spectrometer, a part of the Moon Impact Probe (MIP), was designed to measure various gases in the mass range up to $300 \mathrm{amu}$ present in the lunar environment. Thus the instrument consignment included stereo camera for terrain mapping, radar, two X-ray cameras, three hyperspectral cameras, radiation monitor, solar wind analyser and Moon Impact Probe. In this way, various instruments (Figure 1) formed an integrated set to meet the objectives of Chandrayaan-1. These instruments have been described earlier (e.g. [8-11]).

Chandrayaan-1 was a polar orbiter, orbiting at a nominal altitude of $100 \mathrm{~km}$ with a period of about $118 \mathrm{mi}$ nutes around the Moon, exploring both the poles during every orbit. The orbit was raised to $200 \mathrm{~km}$ towards the end of the mission. Five years have passed since the mission was completed and most of the data have been analysed and published. It is therefore an appropriate time to summarise important results and review the scientific outcome of the mission.

\section{International collaboration}

International collaboration is a stated policy of ISRO since the inception of the Thumba Rocket Launching Station in 1963, which, shortly afterwards, was dedicated to the United Nations. Collaborative rocket flights with other countries were undertaken regularly from Thumba. After the five Indian baseline experiments for the Moon mission were finalised, it was decided to invite collaborative proposals from other countries as well. Based on the proposals received, six payloads from Bulgaria, European

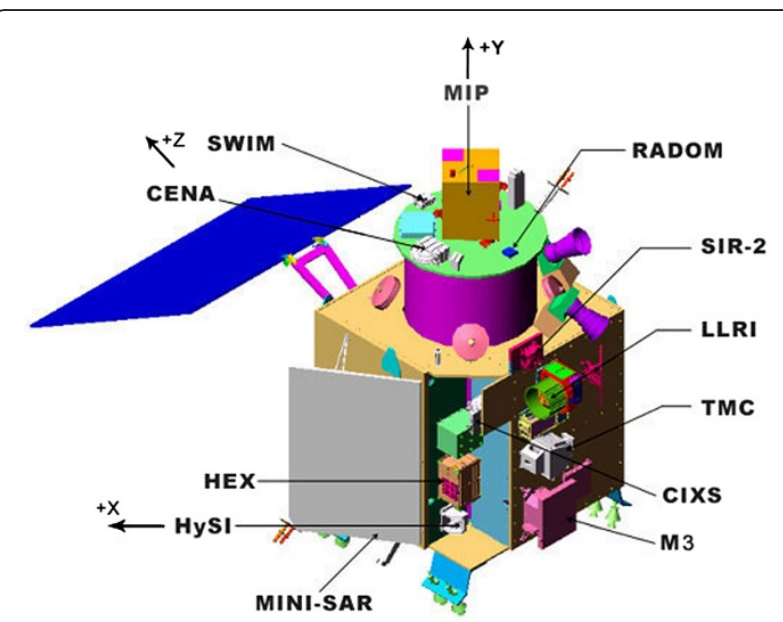

Figure 1 Sketch of Chandrayaan-1 lunar craft integrated with all the instruments. (http://www.isro.gov.in) [11].
Union (mainly Germany and Sweden), United Kingdom, and United States, some in collaboration and others as guest payloads were accepted for the Chandrayaan1 mission. In all, about a dozen nations, besides India, participated in this mission, transforming planetary exploration program, from an individual country's or bilateral enterprise, into a global cooperative effort. Following this model of cooperation, future missions can be economically, speedily and effectively conducted.

\section{Review of science results}

Results obtained by the Chandrayaan- 1 mission have given an insight into various surface-atmosphere interaction processes operating in the lunar environment, further evidences of a global magma ocean on the Moon in the past and indication of recent volcanic activity on the Moon, suggesting that the Moon is still active and dynamic. This is in contrast to the concepts prevailing before Chandrayaan-1 mission when the Moon, based on the study of Apollo rocks, was considered to be bone dry and dormant with little geological activity. It was believed that nothing much happens on the Moon except micrometeorite and meteorite impacts resulting in excavation of the surface, erosion of rocks and creation of regolith. Based on the analysis of lunar samples, it was believed that the Moon is rich in refractory elements and poor in volatiles, leading to theories of hot origin of the Moon. We summarise a few important results here, which have revised some of these concepts. Some results related to lunar geology have been summarised by Chauhan et al. [12].

\section{Lunar environment}

Moon has a very tenuous atmosphere. Enormous amount of water/ice, buried or mixed with the surface soil was discovered in the lunar polar regions by neutron detector on board Lunar Prospector mission [13] but not much was known about the processes operating in the atmosphere and its interaction with the lunar surface. Observations made by four experiments i.e. $\mathrm{CHACE}, \mathrm{M}^{3}$, Mini SAR, and SARA contributed significantly to the understanding of the processes operating on the lunar surface rocks, in the lunar atmosphere and atmosphere-surface interaction. This evidence of an active hydrosphere on the Moon has been a major result of the Chandrayaan-1 mission.

The Chandrayaan Altitudinal Composition Explorer (CHACE) consisting of a mass spectrometer, in addition to a visible imaging camera and altimeter, was placed in the Moon Impact Probe. On 14th November, 2008, the probe was separated from Chandrayaan-1 lunar craft at an altitude of about $100 \mathrm{~km}$ and, as it descended towards the Moon's surface, it took nearly 3000 pictures of the Moon's surface features and 650 mass spectra of lunar atmospheric constituents, covering latitudinal range of $20^{\circ} \mathrm{N}$ to the south pole, during lunar day. The first important 
result was that the lunar atmosphere, with an atmospheric pressure of about $6.7 \times 10^{-5} \mathrm{~Pa}$ was at least two orders of magnitude denser than expected $[14,15]$. The atmosphere was made of several species of which mass (amu) 18, 44, 17 and 28 were the most dominant. In addition, small but clear signals of mass 36 and 40 were also detected [16]. The mass spectra also revealed several other minor constituents (with some unknown species with mass 94). If mass 18 is attributed to $\mathrm{H}_{2} \mathrm{O}$ and 44 to $\mathrm{CO}_{2}$, then it was observed that the concentration of $\mathrm{H}_{2} \mathrm{O} / \mathrm{CO}_{2}$ increased towards the lunar surface, with decreasing altitude, as it approached the south pole. The presence of $\mathrm{H}_{2} \mathrm{O}$ has since been corroborated by other experiments, as we shall see below. Carbon dioxide was observed earlier by Apollo 17 LACE experiment during pre-dawn period [17] but the high value of $\mathrm{CO}_{2}$ measured by $\mathrm{CHACE}$ is the first direct day time measurement. If this result is free of interferences, absence of other lunar surface or extra-lunar (impactor) sources points towards the possibility of degassing from the lunar interior. This is the first indication of a dynamic Moon in which some gases are being released from shallow or deep interior into its atmosphere. Mass 36 and 40 can be attributed to isotopes of argon, the latter being produced by decay of radioactive ${ }^{40} \mathrm{~K}$ present in rocks and accumulated over the geologic history of the Moon. This observation is consistent with degassing from the lunar interior, based on the parentless, orphan ${ }^{40} \mathrm{Ar}$, observed in lunar soil by Manka and Michel [18] and Heymann et al. [19].

\section{Solar wind implantation and release mechanism}

A significant result was obtained by SWIM (Solar Wind Monitor) which had the capability of directional measurement of hydrogen ions [20]. It measured the solar wind hydrogen ions impinging on the Moon and those which are released by the lunar surface back into the lunar environment. The measurements indicated that the number of $\mathrm{H}$ ions released by the lunar surface is over $10 \%$ of the incident hydrogen ions. This is unexpectedly too large. Saito et al. [21], based on MAP-PACE Experiment on board Kaguya (Selene) found that about 0.1 to $1 \%$ of solar wind ions are reflected or scattered back by lunar surface grains. They explained their energy, which is sometimes higher than the incident solar wind ions, by self-pick up acceleration due to photoionisation followed by gyration about the magnetic field that convects with the solar wind. Holmstrom et al. [22] further developed this model to explain the very high fraction of the returned solar wind ions, seen by SWIM. The high flux of returning ions can be explained by another plausible mechanism in which, when grains are exposed to hydrogen and helium ions, the ions coalesce and form bubbles in the amorphous layer formed by the intense ionisation, its thickness depending on the energy of the ions. The process was observed in laboratory irradiation studies [23]. Similar gas bubbles have also been observed in lunar breccias and grains. These bubbles start forming in lunar surface grains exposed to solar wind ions, in a period of a few years and are stable enough for long time. Eventually these bubbles explode and gases diffuse out and are released in the lunar environment [24]. Recent analysis [25] of the rims of particles collected from comet Itokawa show that helium bubbles are indeed formed just below the surface because of exposure to solar wind and solar flares ions. We therefore suggest the possibility that the returned hydrogen ions seen by SWIM, coming out of the lunar surface, may be the hydrogen accumulated in lunar grains due to past irradiation, coalescing in form of bubbles, released into the atmosphere, ionised in lunar environment and then accelerated by the magnetic field, as proposed by Holmstrom et al. [22]. This efflux would depend on the saturation level of various solar gaseous ions and will be independent of the current incoming solar wind flux. This mechanism explains the large variation seen by Wieser et al. [20] and Saito et al. [21]. Degassing and dissociation of $\mathrm{H}_{2} \mathrm{O}$ can be another possibility. Further work is required to substantiate this proposition.

The Moon Mineralogy Mapper $\left(\mathrm{M}^{3}\right)$ had a near IR sensor which could measure the reflectance spectrum between 0.4 to 3 microns. In the spectra taken near lunar poles, the instrument showed prominent absorption bands at 2.8-3 microns corresponding to $\mathrm{OH} / \mathrm{H}_{2} \mathrm{O}$ but these bands were negligibly small in the low latitude spectra [26]. The production of these ions is attributed to the reduction of lunar silicates containing oxygen by solar wind hydrogen. Whereas $\mathrm{H}_{2} \mathrm{O}$ absorption band clearly indicates presence of water in the thin lunar hydrosphere, $\mathrm{OH}$ can have several sources. LCROSS on the American LRO Mission conducted an exciting experiment by analysing the material ejected as a plume from an artificial crater created by impacting a $\sim 2.5$ ton object (a burnt out engine) in Cabeus crater near the south pole of the Moon. It found several species like methane, ethane, methyl alcohol, $\mathrm{CO}_{2}, \mathrm{NH}_{3}, \mathrm{H}_{2} \mathrm{~S}, \mathrm{OH}, \mathrm{CO}_{2}$ etc. besides water [27]. The alcohols can dissociate and give rise to $\mathrm{OH}$ ions in the environment. The LAMP observations Gladstone [28] onboard LRO indicated presence of $\mathrm{CO}, \mathrm{H}_{2}$ and $\mathrm{Hg}$ in the impact plume. Such ions, present in the lunar regolith, can slowly diffuse out into the environment. Thus Chandrayaan-1 and LRO data together suggest an active lunar environment.

Impact of meteorites is the most dominating process on the Moon, which excavate and modify the lunar surface. Meteorites, comets and asteroids bring in water and many volatile elements (including rare gases) which are deficient on the Moon. Secondly, charged particles, i.e. low energy solar wind and energetic solar flares, consisting mainly of hydrogen and helium, in absence of any 
internal magnetic field of the Moon, can reach the ground and get implanted in surface layers of the lunar dust and rocks. The higher energy galactic cosmic rays penetrate up to a couple of meters. On the other hand, sputtering and thermal desorption release some of these gases and volatile elements into the lunar environment. Some observations, like large amount of $\mathrm{CO}_{2}$ observed by $\mathrm{CHACE}$ and some of the compounds observed by LCROSS, discussed above, point to the possibility of their degassing from the lunar regolith or from the lunar interior. As already mentioned, the possibility that the gases are released from the deep lunar interior is favoured by the observation of re-implanted, parentless, excess ${ }^{40} \mathrm{Ar}$ in lunar soil $[18,19]$. Lunar Transient Phenomena (LTP) also point towards sudden release of gases from the lunar depths [29]. Ina structure, a well known morphological anomaly on the Moon, is understood to have been formed by voluminous degassing from the lunar interior [30]. Decay of long lived radioactive elements like uranium, thorium and potassium, and galactic cosmic ray interactions produce a large number of secondary charged particles, neutrons, gamma rays etc. in the upper layers of the Moon, some of which might easily escape into the atmosphere. Radon isotopes are produced in the decay chains of uranium and thorium and, under favourable conditions, some of the radon could also diffuse out into the lunar environment, as discussed below.

Figure 2 schematically shows some of the phenomenon which operate in the lunar environment. As a consequence of the thermal velocity acquired in the lunar environment and lunar gravity, the particles and volatile species follow ballistic trajectory, hopping from one place to another, drifting from hot lunar day $(\sim 400 \mathrm{~K})$ to the

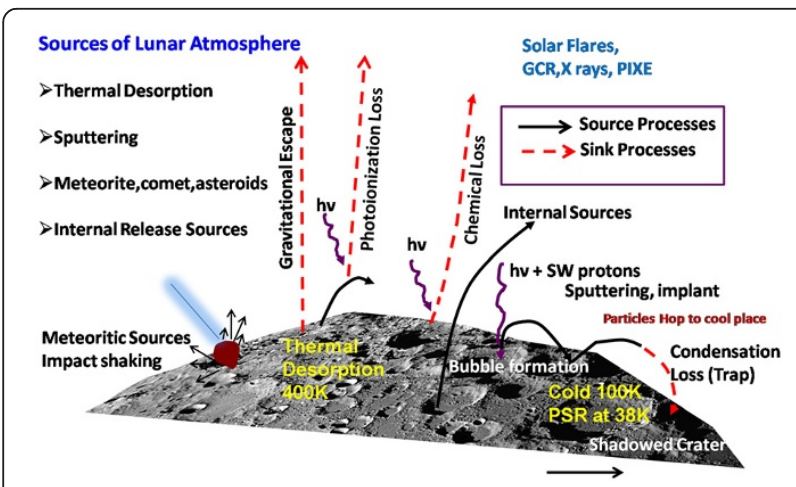

Figure 2 Lunar atmosphere-hydrosphere-surface exchange processes are schematically shown. The radiation present in the lunar environment, besides sunlight, consists of solar wind, solar flares, galactic cosmic rays, $X$ rays and proton induced $X$ rays. Both sinks (gravitational escape, photoionisation loss, chemical loss and condensation of particles at the cold traps) and sources (thermal desorption, sputtering, material brought in by meteorites, comets and asteroids, and internal sources and gases released by bubbles formed in lunar grains) in the environment are shown. cold night side ( 100 K), depositing on the grain surfaces and getting reemitted, eventually getting deposited at the lunar poles where some crater floors are under perennial darkness with extremely low temperatures of about $40 \mathrm{~K}$.

\section{Lead-210 as tracer for volatile transport on Moon}

Radon-222 (half life 3.8 days) is produced in the decay chain of uranium present in the Moon. There is a competition between its decay and diffusion out of the grains. For plausible values of the diffusion coefficient, most of it would decay within the Moon, but if cracks and faults are present, and also due to impacts, some of it could escape into the atmosphere. Some radon would also diffuse out of the surface rocks and grains into the atmosphere. Radon atoms, in the atmosphere, would hop around on the Moon in ballistic trajectory, as it decays into its daughter nuclides and the surviving radon would eventually get deposited in the cold traps. There it would disintegrate through alpha decay to a series of short lived nuclides, eventually to ${ }^{210} \mathrm{~Pb}$ (half life 21.8 years) and ${ }^{210} \mathrm{Po}$ (138 days) [31]. Having a reasonably long life, ${ }^{210} \mathrm{~Pb}$ would persist for some time as an atomic layer, akin to a paint, on lunar rocks and grains. The $46.5 \mathrm{KeV}$ gamma rays associated with its decay could be detected from an orbiter if a suitable sensor is used. This, in turn, could be used to identify regions where radon is leaking at a high rate or where it is ultimately deposited. Excess of ${ }^{210} \mathrm{Po}$ (over its parent ${ }^{222} \mathrm{Rn}$ ) was observed by Turkevich et al. [32] by an alpha spectrometer at Surveyor sites. Gorenstein et al. [33], using alpha spectrometer onboard Apollo spacecraft, found that the edges of several mare, specially dark haloed craters around Mare Serenitatis as also crater Aristarchus, had higher ${ }^{222} \mathrm{Rn}\left({ }^{210} \mathrm{Po}\right)$ concentration compared to their surroundings. Chandrayaan-1 and other recent orbiter missions have shown that the dark regions of haloed craters are made up of basalts [12,34]. The excess ${ }^{210}$ Po observed may be a consequence of relatively high uranium in these basalts. The diffusion coefficient of lunar soil and different types of rocks has not been experimentally measured. Terrestrial rocks generally have a value of diffusivity around $10^{-11} \mathrm{~m}^{2} / \mathrm{s}$ and Lindstrom et al. [35] gave a limit of $<3 \times 10^{-12} \mathrm{~m}^{2} / \mathrm{s}$ in the lunar soil core, based on absence of any signal from its top layer. Bhandari et al. [31] calculated the amount of excess ${ }^{210} \mathrm{~Pb}$ expected on the lunar surface, assuming a set of values of diffusion coefficient ranging between $10^{-12} \mathrm{~m}^{2} / \mathrm{s}$ to $10^{-11} \mathrm{~m}^{2} / \mathrm{s}$ and found that it should be about 50 to 500 times higher than its in situ production. Moreover, its concentration would depend on the average rate of environmental radon deposited over the mean life of ${ }^{210} \mathrm{~Pb}$ and not as much on the uranium concentration of the local terrain.

The High Energy X-ray Spectrometer (HEX), onboard Chandrayaan-1, was designed to measure photons in the range of $30-270 \mathrm{KeV}$ emanating from the lunar surface. 
Naturally occurring radioactive ${ }^{238} \mathrm{U}$ and ${ }^{232} \mathrm{Th}$ series nuclides give several gamma rays in this energy range, of which two (238-242 KeV and $46.5 \mathrm{KeV}$ ) regions were of special interest. The $238.6 \mathrm{KeV}$ and $242 \mathrm{KeV}$ gamma rays are produced in the decay of ${ }^{212,214} \mathrm{~Pb}$ which are representative of the concentration of Th and $U$ respectively in the lunar terrains and the $46.5 \mathrm{KeV}$ gamma rays come from ${ }^{210} \mathrm{~Pb}$, produced from the decay of ${ }^{222} \mathrm{Rn}$, as discussed above. The surface concentration of ${ }^{210} \mathrm{~Pb}$ would depend on the concentration of its parent ${ }^{238} \mathrm{U}$ in the surface rocks plus the amount of radon leaking from the lunar interior which, in turn, would depend on the average diffusivity of the lunar soils and rocks [31]. Because of the limited time of observation available, HEX was operated only for a short period. The results, integrated over all terrains, including the lunar poles for better statistical precision, allowed Vadawale et al. [36] to determine the background spectra in the 30 to $300 \mathrm{KeV}$ energy region, whose shape is in conformity with the predicted spectra, though with some energy shift. The energy shift is possibly because of change in sensitivity of the spectrometer due probably to higher than optimum sensor (Cadmium-Zinc-Telluride, CZT) temperature. The absence of ${ }^{210} \mathrm{~Pb}$ signal allows us to estimate that the diffusion coefficient of radon in the soil under lunar conditions is $<10^{-11} \mathrm{~m}^{2} / \mathrm{s}$.

\section{Detection of water}

There are some reports indicating presence of water/ice on the Moon by Clementine mission [37] but the first unambiguous detection was made by Feldman et al. [13] in lunar polar regions based on the fluxes of fast and epithermal neutrons, measured by neutron detector onboard Lunar Prospector. They also estimated that the amount of water/ice, buried or mixed with soil, could be billions of tons, at each of the north and south poles of the Moon. Chandrayaan-1 was designed to provide further information on water in the lunar environment.

\section{Water/Hydroxyl ions in the environment}

The tenuous lunar environment may have many sources of water; the surface layer is like a permafrost, in complex and active exchange with the atmosphere. The various atoms and molecules released into the atmosphere get ionised by charge exchange with the incoming solar wind, reabsorbed by rock surfaces and released back into the atmosphere, as the rocks are sputtered by the solar wind and eroded by micrometeorite impacts. Thus there are sources and sinks of various constituents in the lunar atmosphere. The photons, X-rays etc., besides charged particles, coming from sun also contribute to the processes operating in the atmosphere. Gravitational escape, when the thermal velocity exceeds the escape velocity, and photoionisation are the main loss mechanisms.
Some of the processes operating in the atmosphere and surface rocks, their sources and sinks are schematically shown in Figure 2.

\section{Sub surface water/ice}

The Synthetic Aperture Radar (Mini-SAR) working at 2.2 $\mathrm{GHz}$ could penetrate subsurface regions, of up to about a meter [38]. Working in active mode, it was designed to transmit circularly polarised signal and receive the scattered signal back. The sense of reflected polarised signal and its ratio to the incident signal (Circular Polarisation Ratio, CPR) depends on the dielectric constant of the scattering material and therefore its values can distinguish water from soil and can be used as an indicator of presence of water-ice. But multiple surface scattering or volume scattering due to roughness of moon's surface also influence CPR and can mimic water-ice [38-40]. To distinguish craters with water ice at their base and freshly formed craters with rough terrain, a procedure was developed, using the criteria that freshly formed craters should show high CPR only in their rough ejecta material consisting of fresh fragments lying outside the crater, and not inside .i.e. crater floor, which is relatively smooth. Therefore, the CPR was compared at the rim, ejecta material outside the rim and crater floors, identifying them with the help of TMC images. Thus freshly formed craters could be identified and distinguished. Water-ice is normally expected to reside at the crater base inside the permanently shadowed craters. In this way, several craters in both, the north and south polar regions, were examined in detail. Even after excluding fresh craters, some craters with anomalous CPR remained which were attributed to presence of water/ice. Such craters exist at both the poles although some water-ice bearing craters were also found at lower latitudes. Their number, however, increased pole wards.

It is well known that meteorites, comets and asteroids contain water and they have been impacting on the Moon throughout its geological history. Furthermore, water together with other volatiles, due to the very high temperatures on the lunar day side and lowest temperatures at the base of the permanently shadowed craters will eventually be transported and deposited on the poles. Thus water deposited at the poles is a mixture of all types of water present on the moon, i.e. exogenous (impact), endogenous (degassing, volcanic) and water produced by reduction of lunar oxides by solar wind protons. If water is brought in by comets and asteroids, their other constituents must also be seen on Moon. This appears to be the case as LCROSS has reported a hoard of volatiles, including alcohols, sulfur compounds etc. [27], unlikely to be indigenous to Moon but found in abundance in the interplanetary objects like comets. Furthermore Pieters et al. [26] found that the distribution of water seen by $\mathrm{M}^{3}$ is different from 
the distribution of water found by Lunar Prospector neutron spectrometer. This observation hints at different sources of the two waters. Since water detected by $\mathrm{M}^{3}$ is distinctly surface correlated and is due to insitu production by solar wind interaction, the water in the deep craters may be predominantly imported impact water.

\section{Endogenic water}

Saal et al. [41] have reported presence of endogenic water and other volatiles (e.g. F, Cl, S) in the lunar volcanic glasses. Recently Bhattacharya et al. [42], Srivastava et al. [43] and Klima et al. [44] have studied spectra taken by $\mathrm{M}^{3}$ at several locations of Moon and identified enhanced signatures of $\mathrm{OH} / \mathrm{H}_{2} \mathrm{O}$ in Compton Belkovich Volcanic Complex, around young flows in the Lowell crater and central peaks of Bullialdus crater, compared to their surrounding regions. Bhattacharya et al. [42] found evidence of hydrated magma indicating that episodic and explosive magmatic events bring with them water which is responsible for hydration of the magma. Similar signatures have also been found in silicic provinces of Hansteen alpha [45] and Gruithesen domes.

\section{Sources of water}

Thus all the three types of water i.e. water inherited during formation of the Moon, now coming out with volcanism (endogenic water, [41-44]), that brought in by impactors over lunar history (cometary and asteroidal water), found deposited in polar regions, together with other apparently non-lunar volatiles (alcohols etc., [27]), and water continuously being produced by reduction of lunar oxides by solar wind hydrogen, found in the lunar surface environment [26], have been confirmed by Chandrayaan-1 and subsequent missions (LCROSS and LEND and LAMP on LRO). The distribution of waterice in polar regions is generally consistent with the earlier results of Feldman et al. [13].

\section{Early evolution of the moon}

Based on the lack of volatiles and excess of refractories in the bulk Moon, compared to the Earth, and similarity of isotopic ratios of several elements (e.g. O, Si, K) in the Moon and the Earth, as also dynamic (orbital and angular momentum) considerations, the Moon is believed to have been formed by a giant impact on an infant Earth by a large asteroid [1]. The ejected material went in to a circum-earth orbit and quickly accumulated to form the Moon. This envisages hot formation of the Moon, depleted in volatiles and rich in refractories. Pritchard and Stevenson [46] have assessed the thermal state of the Moon originating from giant impact and described a plausible scenario in which the whole Moon would be above the solidus temperature. Recent results from GRAIL mission, indicating a relatively thinner crust of the Moon, only about $30 \mathrm{~km}$, as compared to the earlier estimate of 45$60 \mathrm{~km}$ thickness significantly reduces the refractory inventory of the Moon and make it comparable to that of the Earth [47]. Therefore the high temperature origin of the Moon may have to be re-examined. In any case, the presence of a global anorthositic crust suggests that the crust should have formed by the lighter refractory $\mathrm{Al}-\mathrm{Ca}$ rich plagioclase floating in the magma pool. There was so far no evidence that the magma ocean was global in areal extent. The global scale melting up to a few hundred $\mathrm{km}$ depth of the Moon would be, if it had happened, the first significant event in the evolution of Moon. Recently Elardo et al. [48] has discussed the formation of the lunar crust from completely molten Moon. The results discussed below support the global magma ocean hypothesis but cannot distinguish between total or incomplete melting of the Moon.

As the magma ocean cooled, fractional crystallization and differentiation took place due to which the heavier minerals of Fe, $\mathrm{Ti}$ and $\mathrm{Mg}$ sank at the bottom of the pool and the lighter minerals, the calcium aluminum silicates (along with some rafted mafics) floated to form the crust. The formation of anorthositic layer at the top and ilmenite-pyroxene layer below, in a lava pool is shown schematically in Figure 3. Their separation depends on the depth of the lava pool and time available for solidification of the crust. Spectral Profiler data from Kaguya and $\mathrm{M}^{3}$ data from Chandrayaan-1 missions have provided definitive spectral evidences for the presence of crystalline anorthosite massifs of regional dimensions across the Moon's surface. Matsunaga et al. [49], based on spectral profiler data obtained from Kaguya mission reported iron bearing crystalline plagioclase on the far side of the Moon and Ohtake et al. [50], based on Multiband Imager on Kaguya mission, found high abundance of crystalline plagioclase indicating pure anorthosite (PAN) on the Moon. Subsequently signatures of extensive crystalline plagioclase were reported from $\mathrm{M}^{3}$ imaging spectroscopy data in the Orientale basin, Moscoviense basin, Schrödinger Basin, Tsiolkovsky crater, Tycho crater and at several other sites on the Moon (see e.g. [34,51,52]). These observations of more than 200 sites widely distributed all over the Moon favor the possibility that magma ocean was global in extent. Even so, to prove the existence of magma ocean, it is essential to show that iron and magnesium rich dense minerals such as spinels, olivines and pyroxenes exist below the crust. The orbiters only see the surface material and do not have access to the deeper Moon. However, there are two types of events which bring up the deeper interior material to or near the surface [53] viz. (i) large impacts: the central hills/peaked ring of large craters are the rebound material excavated from large depths and (ii) volcanic/plutonic events which bring deep material up through dykes. We summarise here some results on a 


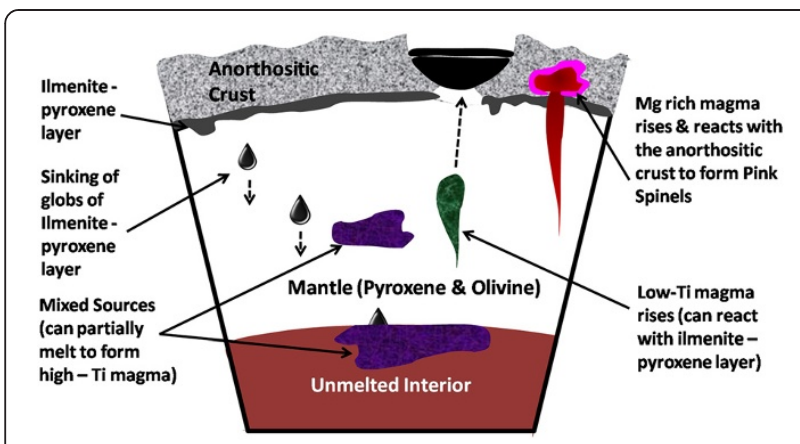

Figure 3 Cross section (not to scale) of upper part of the Moon depicting the magma ocean concept resulting in the formation of anorthositic crust and mafic mantle based on part melting of the Moon. Subsequent processes resulting in the formation of secondary crust (mare basalt, Mg spinel anorthosite) are shown schematically (modified after [79]). Other models depicting total melting of the Moon have been discussed by Pritchard and Stevenson [46] and Elardo et al. [48].

number of craters and basins, spread all over the Moon, which further strengthen the hypothesis of global extent of excavated deep seated dense minerals.

\section{Mg-spinel anorthosite across the moon}

The existence of $\mathrm{Mg}$-spinel on the Moon was known from the study of lunar samples. However, it was always found to be associated with mafic minerals. The $\mathrm{M}^{3}$ data with high spectral resolution and wide spectral coverage identified sites showing Mg-spinel anorthosite (devoid of olivines and pyroxenes and having $\mathrm{FeO}<5 \mathrm{wt} \%$ ) along the rings of Moscoviense basin on the far side of the Moon [54]. These were also found in the central peak of Theophilus crater along the ring of Nectaris basin $[55,56]$.

Other notable occurrences of Mg-spinel anorthosite exposures reported from $\mathrm{M}^{3}$ data include those from Lowell crater in the Orientale basin [43], central peak of Tycho crater [34], rim of Endymion crater [57], and central peaks of 24 craters well distributed across the lunar surface [58]. Association of Mg-spinel anorthosites with several craters and basins and their ubiquitous occurrences across the Moon [59] indicate presence of a deep-seated global $\mathrm{Mg}$ rich layer, thereby favoring global melting of the lunar surface. A similar scenario has been proposed by Pieters et al. [60] to explain the occurrence of Mg-spinel anorthosites. It may be noted that alternative hypotheses have been proposed for the formation of spinel anorthosites [59,61,62]. For example, Prissel et al. [61] proposed reaction between $\mathrm{Mg}$-suite/gabbroic magma with the anorthositic crust and Yamamoto et al. [59] suggested melting of the crust and mantle during large basin forming impacts. The basic ingredients for $\mathrm{Mg}$ spinel production i.e. an anorthositic crust and mafic mantle require global melting.

\section{Evidence of recent volcanism}

Most of the lunar mare basalts are very old $(>3 \mathrm{Ga})$ and the highlands are even older. Dating of Apollo and Luna basalts indicated ages ranging between 4.2 and 3.1 Ga during which large basins were filled with lava and solidified. This was taken as an evidence that the Moon has been volcanically inactive for aeons, although occasionally some younger basaltic surfaces with ages of up to $\sim 1 \mathrm{Ga}$, were found (e.g., [63-67]). Chandrayaan-1 results and data from other recent missions viz. Kaguya and LRO show evidences of more recent basaltic and silicic volcanism and tectonic activities on the Moon [12,34,43,68,69]. The Diviner thermal emissivity data of LRO provided compositional information of the young silicic Compton Belkovich region [68] and $\mathrm{M}^{3}$ data aided in deciphering the composition of fresh flows and pools in the Tycho and Lowell craters [34,43]. The Kaguya digital model (TC DTM) has been used for topographical studies [43] and panchromatic images from all these missions, especially the narrow angle camera on LRO mission (LROC-NAC), have been used to delineate fine morphological details. We summarise here some of the results which indicate volcanic activity as recent as 2 million years ago.

Tycho ( $~ 85 \mathrm{~km}$ diameter) is $\sim 108 \mathrm{Ma}$ old crater located in the southern near side lunar highlands. Surface topography, morphology and spectral reflectance studies of its central peak by Chauhan et al. [34] have furnished evidences of freshly formed basaltic/gabbroic melt pools, vents, channels, and domes that were created after the formation of the crater, indicating late stage impact induced volcanism in the region.

It is difficult to differentiate impact melts and volcanic flows through remote sensing because of their similar end products. However, by combining topographical, morphological with compositional studies in the geological context, we can derive some clues to the mechanism by which the flows have formed. Such a study has been carried out inside the $\sim 66 \mathrm{~km}$ diameter Lowell crater at $13.0^{\circ} \mathrm{S}$, $103.4^{\circ} \mathrm{W}[43,70]$. Here, the resurfacing extends from a small satellite crater on the eastern wall and terminates on the crater floor. The basaltic flows are confined to a possible graben like structure. Analogs of Hawaiian volcanic features on the Earth such as volcanic cone, pyroclastics, superposed flows of different generations and secondary source regions have been found suggesting that the young flows are volcanic in origin and not impact melts. The order of superposition of different aged units, exhibiting different composition, suggest that all these flows cannot be co-genetic and that the fresh basaltic flows might be a manifestation of late stage, unusually recent volcanic activity on the Moon, $\sim 2$ to $10 \mathrm{Ma}$ ago.

In addition to these, $\sim 50$ potential candidates for recent volcanism $\sim 18$ to $58 \mathrm{Ma}$ old, have been identified using LROC-NAC and $\mathrm{M}^{3}$ data [71]. To summarize, 
these studies indicate that the interior of the Moon may still be molten and that the Moon may not be as quiet as believed earlier. These data, taken all together suggest a dynamic and volcanically active Moon.

\section{Chemical composition of southern highland crust}

We have discussed above some rock types with mineral composition different from the known rocks on Moon. The Chandrayaan-1 $\mathrm{X}$ ray Spectrometer (C1XS) measured chemical composition ( $\mathrm{Mg}, \mathrm{Al}, \mathrm{Si}, \mathrm{Ca}, \mathrm{Ti}$ and $\mathrm{Fe}$ ) of highland rocks in the nearside southern hemisphere of the Moon, near Tycho, by their characteristic fluorescent X-rays excited by the solar X-rays [72]. The high resolution X-ray spectrometer worked exceptionally well and established that the terrain has a composition poor in $\mathrm{Ca}, \mathrm{Mg}$ and $\mathrm{Fe}$ and richer in $\mathrm{Al}$ compared to other known highland rocks. In some of the spectra, pertaining to other terrains, the X-ray spectrometer was also able to detect sodium.

\section{Conclusions from Chandrayaan-1 results}

Chandrayaan-1 identified hydroxyl, water molecules, $\mathrm{CO}_{2}, \mathrm{~N}_{2}$ and Ar etc. in the lunar surface environment which indicate an active lunar hydrosphere. Thus the lunar surface appears to be in dynamic exchange with the surface bounded exosphere. The mission established sub-surface ice layers below permanently shadowed craters which agree with the Lunar Prospector neutron monitor and the LEND results [73]. The solar wind monitor detected a significant fraction (>10\%) of implanted solar wind hydrogen ions coming from the lunar surface, which can be explained by slow coalescence of solar wind implanted ions in the irradiated lunar grains into bubbles, over their irradiation history, and subsequent release into the lunar environment. The three types of water, endogenic water, impactor water and solar wind-reduction water have been found on Moon by Chandrayaan-1.

The rock types (Mg-spinel and crystalline anorthosite) and their wide spread distribution indicate global melting of the surface regions of the Moon validating global magma ocean hypothesis. Identification of young ( 2 to $100 \mathrm{Ma}$ ) basaltic regions and tectonic features shows that Moon might still be volcanically and dynamically active. The X-ray fluorescence spectrometer gave well resolved characteristic X-ray peaks for Low-Z elements ( $\mathrm{Na}$ to $\mathrm{Fe}$ ) and found a highland anorthosite, poor in $\mathrm{Ca}$, $\mathrm{Mg}$ and $\mathrm{Fe}$ and rich in $\mathrm{Al}$, compared to other Apollo highland rocks.

We have discussed only a few results obtained by Chandrayaan-1 which essentially provide evidence for an active Moon, with its surface material in active exchange with its environment. Other notable results include discovery of mini- magnetosphere on Moon [74], identification of a possible habitable lava tube in Oceanus
Procellarum [75] and radiation dose variations as the lunar craft went from Earth to the Moon [76].

\section{Future plans}

Following the success of Chandrayaan-1, ISRO has initiated more planetary missions. We discuss here two missions: Chandrayaan-2, which is in advance stage of readiness and Mars Orbiter Mission, which was launched in November 2013 and is now on its way to Mars [11].

\section{Chandrayaan-2}

Chandrayaan-2 is proposed to be an Orbiter-LanderRover mission and is designed to be a technical as well as a scientific mission. The primary technical objectives are to test the capability of soft landing at a predetermined site on the Moon and to perfect the technology of rover navigation and hazard avoidance. The orbiter, lander and rover are equipped with several instruments to validate and extend the findings of Chandrayaan-1 $[11,77]$. All the five payloads on Chandrayaan-2, which will circle the Moon at an altitude of about $200 \mathrm{Km}$, are modified versions of payloads on Chandrayaan-1, i.e. Neutral Mass Spectrometer (CHACE-2), a large area soft X-ray spectrometer (CLASS) with Solar X-ray Monitor (XSM), a dual L and S band Synthetic Aperture Radar (SAR), an Imaging Infrared spectrometer (IIRS) and a Terrain Mapping Camera (TMC-2). The scientific objectives include chemical analysis from the orbit and on the surface using the rover. Chandrayaan Large Area Soft Xray Spectrometer will map the major elements present on the lunar surface by measuring characteristic X-rays induced by Solar X-rays which will be monitored by XSM. The dual band Synthetic Aperture Radar will probe the first few metres of the lunar surface for the presence of different constituents and will enable us to unambiguously distinguish CPR values generated by water/ice and multiple scattering by fresh ejecta. Imaging IR Spectrometer will map the lunar surface over a wide wavelength range for study of minerals, water molecules and hydroxyl ions. Neutral Mass Spectrometer is designed to carry out a detailed study of the lunar exosphere and confirm the presence of $\mathrm{CO}_{2}$ and $\mathrm{H}_{2} \mathrm{O}$, Ar etc. found by Chandrayaan-1 impact probe. The images obtained by Terrain Mapping Camera will be used for preparing a three-dimensional map essential for studying the lunar mineralogy and geology.

The Rover will carry two payloads: The Laser Induced Breakdown Spectroscope (LIBS) and Alpha Particle XRay Spectrometer (APXS), for elemental analysis of the lunar surface near the landing site. Moon Electrostatic Dust Analayser (MESDA), consisting of two instruments namely Lunar Surface Potential detector and Lunar Dust Detector and Chandra's Surface Thermal Experiment (CHASTE) which may determine the thermal profile up 
to $10 \mathrm{~cm}$ depth in the regolith are being considered for the Lander. Two sites near the south pole are under consideration for landing the Lander-Rover.

\section{Mars orbiter mission}

The Mars Orbiter Mission (MOM) is a technologicalscientific mission [78]. The main technological challenges are autonomous operation because of long time delay in communication (6 to 43 minutes) due to the large distance of Mars.

It is proposed to have a highly elliptic orbit (perigee $\sim 370 \mathrm{~km}$ to apogee of $\sim 80000 \mathrm{~km}$ ) going across the upper atmosphere and ionosphere of Mars, which would enable the study of altitudinal variations of several atmospheric constituents during every orbit. The instruments onboard are (i) Methane Sensor (MMS) for identifying sources of methane, which is prospective indictor of biologic and geologic activity on Mars, and its spatial and seasonal variation (ii) Lyman Alpha $\mathrm{D} / \mathrm{H}$ Photometer (LAP) for isotopic measurements of hydrogen in martian atmosphere to understand the origin of martian water and verifying the escape processes under weak martian gravity, (iii) Thermal infrared Imaging Spectrometer (TIS) for measurement of martian surface temperatures, and (iv) Martian Exospheric Composition Explorer (MENCA) for studying the neutrals in the martian exosphere and their seasonal variations. In addition (v) a Martian colour Camera (MCC) has been included. The mission, launched on 5th November, 2013, is expected to arrive at Mars in September 2014 and will continue observation from highly elliptical orbit around Mars for a period of about six months.

There is an interesting possibility as comet C/2013 A1 is expected to fly close to Mars, about a month after MOM arrives at the red planet. Current orbital estimates of the comet show that Mars may be engulfed by the comet tail. This will provide a unique opportunity of measuring $\mathrm{D} / \mathrm{H}$ and methane in the comet with instruments on board MOM.

\section{Competing interest}

The authors declare that they have no competing interests. We are exempt from paying article processing charges. We do not hold stock or shares in any organization that may gain or loose financially from publication of this manuscript. We are not applying for any patents. There are no non financial competing interests.

\section{Authors' contributions}

Both the authors Prof. NB and NS have jointly drafted the manuscript and participated in interpretation and have read and approved the final manuscript. NB modeled the degassing of RADON and formation of bubbles in irradiated grains. He gave the distinguished lecture at the AOGS meeting at Brisbane, Australia. He proposed some of the ideas sketched in Figure 2. NS collected data for young volcanic provinces on the Moon and specifically contributed to reflectance spectroscopy related matter and prepared Figure 3.

\section{Acknowledgements}

This article is based on the Distinguished Lecture given at the 10th AOGS meeting held at Brisbane in June 2013 and we thank AOGS for exempting page charges. We are grateful to K. Radhakrishnan for encouragement and to A.S. Kirankumar, R. Sridharan, P. Chauhan, R. Sreekumar, S. Narendranath, D. Dhingra, C. Pieters, Shiv Mohan and S.A. Haider for useful discussions and for sharing their data. We acknowledge ISRO for providing facilities for carrying out this work. We thank the reviewers and T. Satoh for their suggestions in improving the manuscript.

Received: 21 October 2013 Accepted: 27 June 2014

Published online: 02 October 2014

\section{References}

1. Hartmann WK, Phillips RJ, Taylor GJ (1986) The origin of the moon. Lunar and Planetary Institute, Houston

2. Canup RM, Righter K (2000) Origin of earth and moon. University of Arizona Press, Tucson, Arizona, USA

3. Zahnle KJ, Sleep NH (1997) Impacts and early evolution of life. In: Thomas PJ, Chyba CF, Mckay CP (eds) Comets and the origin and evolution of life. Springer-Verlag, NewYork, pp 165-208

4. Wieczorek MA, Feuvre ML (2007) Did a large impact reorient the Moon? Icarus 200:358-366

5. Nishida A (2000) The earth's dynamic magnetotail. Space Sci Rev 91:507-577

6. Bhandari N (2002) A quest for the moon. Curr Sci 83:377-393

7. Jain $R$, Dave $H$, Shah AB, Vadher NM, Shah VM, Ubale GP, Manian SB, Solanki CM, Shah KJ, Kumar S, Kayasth SL, Patel VD, Trivedi JJ, Deshpande MR (2005) Solar X-ray Spectrometer (SOXS) Mission on Board GSAT2 Indian Spacecraft: The Low-Energy Payload. Sol Phys 89-122. doi:10.1007/s11207-005-1712-3

8. Bhandari N (2005) Chandrayaan-1: science goals. J Earth System Science 114:699-710

9. Bhandari N (2008) Planetary exploration: scientific importance and future prospects. Curr Sci 94:189-200

10. Goswami JN, Annadurai M (2009) Chandrayaan-1: India's first planetary science mission to the moon. Curr Sci 96:486-491

11. Indian Space Research Organisation (http://www.isro.gov.in "ISRO Satellites: Space Missions")

12. Chauhan P, Kaur P, Ajai, Kiran Kumar AS (2012) Lunar geosciences using Chandrayaan-1: Indian perspective. Proc Indian National Sci Academy 78:239-247

13. Feldman WC, Maurice S, Binder AB, Barraclough BL, Elphic RC, Lawrence DJ (1998) Fluxes of fast and epithermal neutrons from lunar prospector: evidence for water ice at the Lunar Poles. Science 281:1496-1500

14. Sridharan R, Ahmed SM, Das TP, Sreelatha P, Pradeepkumar P, Naik N, Gogulapati S (2010a) The sunlit lunar atmosphere: a comprehensive study by CHACE on the Moon impact probe of Chandrayaan-1. Planet Space Sci 58:1567-1577

15. Sridharan R, Ahmed SM, Das TP, Sreelatha P, Pradeepkumar P, Naik N, Gogulapati S (2010b) 'Direct' evidence of water (H2O) in the sunlit lunar ambience from CHACE on MIP of Chandrayaan I. Planet Space Sci 58:947-950. doi:10.1016/j.pss.2010.02.013

16. Sridharan R, Das TP, Ahmed SM, Supriya G, Bhardwaj A, Kamalakar JA (2013) Spatial heterogeneity in the radiogenic activity of the lunar interior: inferences from CHACE and LLRI on Chandrayaan-1. Adv Space Res 51:168-178

17. Hoffmann JH, Hodges RR Jr (1975) Molecular gas species in the lunar atmosphere. The Moon 14:159-167

18. Manka RH, Michel FC (1971) Lunar Atmosphere as a source of Lunar surface elements. Proc Lunar Sci Conf 2:1717-1728

19. Heymann D, Yaniv A, Walton J (1972) Inert gases in Apollo 14 Fines and the case of parentless Ar40. Lunar Sci Conf Houston 3:1137

20. Wieser M, Barabash S, Futaana Y, Holmstrom M, Bhardwaj A, Sridharan R, Dhanya MB, Wurz P, Schaufelberger A, Asamura K (2009) Extremely high reflection of solar wind protons as neutral hydrogen atoms from regolith in space. Planet Space Sci 57:2132-2134

21. Saito Y, Yokota S, Tanaka T, Asamura K, Nishino MN, Fujimoto M, Tsunakawa H, Shibuya H, Matsushima M, Shimizu H, Takahashi F, Mukai T, Terasawa T (2008) Solar wind proton reflection at the lunar surface: Low energy ion measurement by MAP-PACE onboard SELENE (KAGUYA). Geophys Res Lett 35:L24205

22. Holmstrom M, Wieser M, Barabash S, Fontana Y, Hardwar A (2010) Dynamics of solar wind protons reflected by the Moon. J Geophys Res 115, A06206 
23. Primak W (1963) Radiation induced cavities and exfoliation. J Appl Phys 34:3630-3632

24. Tamhane AS, Agrawal JK (1979) Diffusion of rare gases of solar wind origin from lunar fines as bubbles. Earth Planet Sci Lett 42:243-250

25. Noguchi T, Kimura M, Hashimoto T, Konno M, Nakamura T, Zolensky ME, Okazaki R, Tanaka M, Tsuchiyama A, Nakato A, Ogami T, Ishida H, Sagae R, Tsujimoto S, Matsumoto T, Matsuno J, Fujimura A, Abe M, Yada T, Mukai T, Ueno M, Okada T, Shirai K, Ishibashi Y (2014) Space weathered rims found on the surface of the Itokawa dust particles. Meteoritics Planet Sci 49:188-214. doi:10.1111/maps.12111

26. Pieters CM, Goswami JN, Clark RN, Annadurai M, Boardman J, Buratti B, Combe J-P, Dyar MD, Green R, Head JW, Hibbitts C, Hicks M, Isaacson PR, Klima R, Kramer G, Kumar G, Livo E, Lundeen S, Malaret E, McCord T, Mustard J, Nettles J, Petro N, Runyon C, Staid M, Sunshine J, Taylor LA, Tompkins S, Varanasi P (2009) Character and spatial distribution of $\mathrm{OH} / \mathrm{H} 2 \mathrm{O}$ on the surface of the moon as seen by Moon Chandrayaan I. Science 326:568-572

27. Colaprete A, Schultz P, Heldmann J, Wooden D, Shirley M, Ennico K, Hemalyn B, Marshall W, Ricco A, Elphic RC, Goldstein D, Summy D, Bart GD, Asphaug E, Korycansky D, Landis D, Sollit L (2010) Detection of water in LCROSS ejecta plume. Science 330:463-468

28. Gladstone G (2010) LRO-LAMP Observations of the LCROSS impact plume. Science 330:472-476

29. Crotts A (2008) Lunar outgassing, transient phenomena and the return to the Moon, I: existing data. Astrophys J 687:692-705

30. Schultz PH, Staid MI, Pieters CM (2006) Lunar activity from recent gas release. Nature 444:184-186

31. Bhandari N, Adimurthy V, Banerjee D, Srivastava N, Dhingra D (2004) Chandrayaan-1 Lunar Polar Orbiter: Science goals and Payloads. Proc International Lunar Conference 2003/ ILEWG 5, 16-22 November, Hawaii. American Astronautical Society, Science and Technology Series 108:33-42

32. Turkevich AL, Patterson JK, Franzgrote FJ, Sowinski KP, Economou TE (1970) Alpha radioactivity of the lunar surface at the landing sites of Surveyors 5, 6, and 7. Science 167:1722-1724

33. Gorenstein P, Golub L, Bjorkholm P (1974) Detection of radon emission at the edges of lunar maria with the Apollo alpha-particle spectrometer. Science 183:411-413

34. Chauhan P, Kaur P, Srivastava N, Bhattacharya S, Ajai, Kirankumar AS, Goswami JN (2012) Compositional and Morphological analysis of high resolution remote sensing data over central peak of Tycho crater on the moon: implications for understanding lunar interior. Curr Sci 102:1041-1046

35. Lindstrom RM, Evans JC Jr, Finkel RC, Arnold JR (1971) Radon emanation from the lunar surface. Earth Planet Sci Lett 11:254-256

36. Vadawale SV, Sreekumar P, Acharya YB, Shanmugam M, Banerjee D, Goswami JN, Bhandari N, Umapathy CN, Sharma MR, Tyagi A, Bug M, Sudhakar M, Abraham L (2013) Hard X-ray continuum from lunar surface: results from high energy X-ray spectrometer (HEX) onboard Chandrayaan-1. Adv in Space Res http://dx.doi.org/10.1016/j.asr.2013.06.013

37. Nozette S, Spudis PD, Robinson M, Bussey DBJ, Lichtenburg C, Bonner R (2001) Integration of the Lunar Polar remote-sensing data sets: evidence for ice at the Lunar South Pole. J Geophys Res 106:23253-23266

38. Spudis PD, Bussey DBJ, Baloga SM, Butler BJ, Carl D, Carter LM, Chakraborty M, Elphic RC, Gillis-Davis JJ, Goswami JN, Heggy E, Hillyard M, Jensen R, Kirk RL, LaVallee D, McKerracher P, Neish CD, Nozette S, Nylund S, Palsetia M, Patterson W, Robinson MS, Raney RK, Schulze RC, Sequeira H, Skura J, Thompson TW, Thomson BJ, Ustinov EA, Winters HL (2010) Initial results for the North Pole of the Moon from Mini-SAR, Chandrayaan-1 mission. Geophys Res Lett. doi:10.1029/2009GL042259

39. Mohan S, Das A, Chakraborty M (2011) Studies of polarimetric properties of lunar surface using Mini-SAR data. Curr Sci 101:159-164

40. Mohan S, Das A (2012) Chandrayaan-1 Mini SAR data investigation. Lambert Academic Publishing, Saarbrücken, Germany, p 79

41. Saal AE, Hauri EH, Mario LC, Van Orman JA, Rutherford MC, Cooper RF (2008) Volcanic content of lunar volcanic glasses and the presence of water in the Moon's interior. Nature 454:192-195. doi:10.1038/nature07047

42. Bhattacharya S, Saran S, Dagar A, Chauhan P, Chauhan M, Ajai, Kiran Kumar AS (2013) Endogenic water on the moon associated with non-mare silicic volcanism: implications for hydrated lunar interior. Curr Sci 105:685-691

43. Srivastava N, Kumar D, Gupta RP (2013) Young viscous flows in the Lowell crater of Orientale basin, Moon: Impact melts or volcanic eruptions? Planet Space Sci 87:37-45, http://dx.doi.org/10.1016/j.pss.2013.09.001
44. Klima R, Cahill J, Hagerty H, Lawrence D (2013) Remote detection of magmatic water in Bullialdus Crater on the Moon. Nat Geosci 6:737-741. doi:10.1038/ngeo1909

45. Kaur P, Chauhan P, Ajai (2013) Exposures of Mg-spinel on an evolved silicic lithology Hansteen Alpha on the Moon. Lunar Planet Sci Conf Houston 44:1348

46. Pritchard ME, Stevenson DJ (2000) Thermal aspects of a lunar origin by giant impact. In: Canup RM, Righter K (eds) Origin of the earth and moon. The University of Arizona Press, Tucson, Arizona and LPI, Houston, USA, pp 179-196

47. Wieczorek MA, Neumann GA, Nimmo F, Kiefer WS, Taylor GF, Melosh HJ, Phillips RJ, Solomon SC, Andrews-Hanna JC, Asmar SW, Konopliv AS, Lemoine FG, Smith DE, Watkins MM, Williams JG, Zuber MT (2013) The crust of the moon as seen by GRAlL. Science 339:671-675

48. Elardo SM, Draper DS, Shearer CK (2011) Lunar magma ocean crystallization revisited: bulk composition, early cumulate mineralogy, and the source regions of the Highlands Mg-suite. Geochim Cosmochim Acta 75:3024-3045. doi:10.1016/j.gca.2011.02.033

49. Matsunaga T, Ohtake M, Haruyama J, Ogawa Y, Nakamura R, Yokota Y, Morota T, Honda C, Torii M, Abe M, Nimura T, Hiroi T, Arai T, Saiki K, Takeda H, Hirata N, Kodama S, Sugihara T, Demura H, Asada N, Terazono J, Otake H (2008) Discoveries on the lithology of lunar crater central peaks by SELENE Spectral Profiler. Geophys Res Lett 35, L23201

50. Ohtake M, Matsunaga T, Haruyama J, Yokota Y, Ogawa Y, Morota T, Honda C, Torii M, Miyamoto H, Arai T, Hirata N, Iwasaki A, Nakamura R, Hiroi T, Sugihara T, Takeda H, Otake H, Pieters CM, Saiki K, Kitazato K, Abe M, Asada N, Demura H, Yamaguchi Y, Sasaki S, Kodama S, Terazono J, Shirao M, Yamaji A, Minami S (2009) The global distribution of pure anorthosites on the Moon. Nature 461:236-241. doi:10.1038/nature08317

51. Kramer GY, Kring DA, Nahm AL, Pieters CM (2013) Spectral and photogeologic mapping of Schrödinger Basin and implications for postSouth Pole-Aitken impact deep subsurface stratigraphy. Icarus 223:131-148

52. Cheek LC, Donaldson Hanna KL, Pieters CM, Head JW, Whitten JL (2013) The distribution and purity of anorthosite across the Orientale basin: new perspectives from moon mineralogy mapper data. J Geophys Res. doi:10.1002/jgre.20126

53. Melosh HJ, Ivanov VA (1999) Impact crater collapse. Annual Rev Earth Planet Sci 27:385-415

54. Pieters CM, Besse S, Boardman J, Buratti B, Cheek L, Clark RN, Combe JP, Dhingra D, Goswami JN, Green RO, Head JW, Isaacson P, Klima R, Kramer G, Lundeen S, Malaret E, McCord T, Mustard J, Nettles J, Petro N, Runyon C, Staid M, Sunshine J, Taylor LA, Thaisen K, Tompkins S, Whitten J (2011) Mg spinel lithology: a new lunar rock type on the lunar far side. J Geophys Res 116:E00G08. doi:10.1029/2010JE003727

55. Dhingra D, Pieters M, Boardman JW, Head JW, Isaacson PJ, Taylor LA (2011) Compositional diversity at Theophilus Crater: understanding the geological context of Mg-spinel bearing central peaks. Geophys Res Lett 38, L11201. doi:10.1029/2011G L047314

56. Lal D, Chauhan P, Shah RD, Bhattacharya S, Ajai KAS (2012) Detection of Mg-spinel lithologies on the central peak of crater Theophilus using Moon Mineralogy Mapper (M3) data from Chandrayaan-1. J Earth System Sci 121:847-853

57. Bhattacharya S, Chauhan P, Ajai (2012) Discovery of orthopyroxene - olivine - spinel assemblage from the lunar nearside using Chandrayaan-1 Moon Mineralogy Mapper data. Curr Sci 103:21-23

58. Sun Y, Lin L, Zhang YZ (2013) Detection of Mg-spinel bearing peaks using $\mathrm{M}^{3}$ images. Lunar Planet Sci Conf Houston 44:1393

59. Yamamoto $S$, Nakamura R, Matsunaga T, Ogawa $Y$, Ishihara $Y$, Morota $T$, Hirata N, Ohtake M, Hiroi N, Yokota Y, Haruyama J (2013a) Global distribution of Mg-spinel on the Moon revealed by SELENE spectral profiler. Lunar Planet Sci Conf Houston 44:1768

60. Pieters CM, Hanna KD, Cheek L, Dhingra D, Moriarty D, Parman S, Jackson C, Prissel T (2013) Compositional evolution of the early lunar crust: observed diverse mineralogy of the upper and lower crust. Lunar Planet Sci Conf Houston 44:2545

61. Prissel TC, Parman SW, Head JW, Jackson CRM, Rutherford MJ, Hess PC, Cheek L, Dhingra D, Pieters CM (2013) An "Uncollected" Member of the Mg-Suite: Mg-Al Pink Spinel Anorthosites and their Place on the Moon. Lunar Planet Sci Conf Houston 44:3066

62. Yamamoto S, Nakamura R, Matsunaga T, Ogawa Y, Ishira Y, Morota T, Hirata N, Ohtake M, Hiroi T, Haruyama J (2013) A new type of pyroclastic deposit 
on the moon containing Fe-spinel and chromite. Geophys Res Lett 40:4549-4554

63. Schultz PH, Spudis PD (1989) The beginning and end of lunar mare volcanism. Nature 302:233-236

64. Haruyama J, Ohtake M, Matsunaga T, Morota T, Honda C, Yokota Y, Abe M, Ogawa Y, Miyamoto H, Iwasaki A, Pieters CM, Asada N, Demura H, Hirata N, Terazono J, Sasaki S, Saiki K, Yamaji A, Torii M, Josset UL (2009) Long-lived volcanism on the lunar farside revealed by SELENE Terrain Camera. Science 323:905-908

65. Staid MI, Pieters CM, Besse S, Boardman J, Dhingra D, Green R, Head JW, Isaacson P, Klima R, Kramer G, Mustard JM, Runyon C, Sunshine J, Taylor LA (2011) The mineralogy of last-stage lunar volcanism as observed by the moon mineralogy mapper on Chandrayaan-1. J Geophys Res 106(27):877-27, 900

66. Whitten J, Head JW III, Staid MI, Pieters CM, Mustard JF, Clark R, Nettles JW, Klima RL, Taylor LA (2011) Lunar mare deposits associated with the Orientale impact basin: new insights into mineralogy, history, mode of emplacement, and relation to Orientale Basin evolution from Moon Mineralogy Mapper $\left(\mathrm{M}^{3}\right)$ data from Chandrayaan-1. J Geophys Res 116: EOOG09. doi:10.1029/2010JE00 3736

67. Cho Y, Morota T, Haruyama J, Yasui M, Hirata N, Sugita S (2012) Young mare volcanism in the Orientale region contemporany with the Procellarum KREEP Terraine (PKT) volcanism peak period 2 b. y. ago. Geophys Res Lett 39, L11203

68. Jolliff BL, Wiseman SA, Lawrence SJ, Thanh NT, Robinson MS, Sato H, Hawke BR, Frank S, Oberst J, Hiesinger J, van der Bogert CH, Greenhagen BT, Glotch TD, Paige D (2011) Non-mare silicic volcanism on the lunar far side at Compton-Belkovich. Nat Geosci 4:566-571

69. Watters TR, Robinson MS, Beyer RA, Banks ME, Bell JF III, Pritchard ME, Hiesinger $\mathrm{H}$, van der Bogert CH, Thomas PC, Turtle EP, Williams NR (2010) Evidence of recent thrust faulting on the Moon revealed by the Lunar Reconnaissance Orbiter Camera. Science 329(5994):936-940

70. Srivastava N, Kumar D, Gupta RP (2011) Is the moon still active? In: Proceedings of Conference on Planetary Sciences and Exploration. PRL, Ahmedabad, India, pp 97-98

71. Braden SE, Robinson MS, Stopar JD, van der Bogert CH, Hawke BR (2013) Age and extent of small, young volcanic activity on the moon. Lunar Planet Sci Conf Houston, 44:2843.

72. Narendranath S, Athiray PS, Sreekumar P, Kellett BJ, Alha L, Howe CJ, Joy KH, Grande M, Huovelin J, Crawford IA, Unnikrishnan U, Lalita S, Subramaniam S, Weider SZ, Nittler LR, Gasnault O, Rothery D, Fernandes VA, Bhandari N, Goswami JN, Wieczorek MA, Cook A, Maddison BJ, Swinyard BM, Shrivastava A, Duston CL, Maurice S, Smith D, Anand M, Holland A (2011) Lunar X-ray fluorescence observations by the Chandrayaan-1 X-ray Spectrometer (C1XS): Results from the nearside southern highlands. Icarus 214:53-66

73. Mitrofanov I, Litvak M, Sanin A, Malakhov A, Golovin D, Boynton W, Droege G, Chin G, Evans L, Harshman K, Fedosov F, Garvin J, Kozyrev A, McClanahan T, Milikh G, Mokrousov M, Starr R, Sagdeev R, Shevchenko V, Shvetsov V, Tret'yakov V, Trombka J, Varenikov A, Vostrukhin A (2012) Testing polar spots of water-rich permafrost on the Moon: LEND observations onboard LRO. J Geophys Res 117:E00H27. doi:10.1029/2011JE003956

74. Wieser M, Barabash S, Futaana Y, Holmstrom M, Bhardwaj A, Sridharan R, Dhanya MB, Schaufelberger A, Wurz P, Asamura K (2010) First observation of a mini-magnetosphere above a lunar magnetic anomaly using energetic neutral atoms. Geophys Res Lett 37, L05103

75. Arya AS, Rajsekhar RP, Thangjam G, Ajai, Kiran Kumar AS (2011) Detection of potential site for future human habitability on the Moon using Chandrayaan-1 data. Curr Sci 100:524-529

76. Dachev TP, Tomov BT, Matviichuk YN, Dimitrov PS, Vadawale SV, Goswami JN, De Angelis G, Girish V (2011) An overview of RADOM results for earth and moon radiation environment on Chandrayaan-1 satellite. Adv Space Res 48:779-791

77. Srivastava N, Karanam D eds (2012) Mission story: Chandrayaan-2/LUNA-RESURS. PLANEX Newsletter 2(2):21-22, http://www.prl.res.in/ planex/planexnews

78. Goswami JN, Radhakrishnan K (2013) Indian mission to Mars. Lunar Planet Sci Conf Houston 44:2760

79. Taylor GJ (2000) Recipe for high-titanium lunar magmas, PSR Discoveries., http://www.psrd.hawaii.edu/Dec00/PSRD-highTi.pdf

doi:10.1186/s40562-014-0011-y

Cite this article as: Bhandari and Srivastava: Active moon: evidences from Chandrayaan-1 and the proposed Indian missions. Geoscience Letters 2014 1:11.

\section{Submit your manuscript to a SpringerOpen ${ }^{\circ}$ journal and benefit from:}

- Convenient online submission

- Rigorous peer review

- Immediate publication on acceptance

- Open access: articles freely available online

- High visibility within the field

- Retaining the copyright to your article

Submit your next manuscript at $\gg$ springeropen.com 